\title{
Techniques of Translating A Watchful Distance by Zhou Guoping in China
}

\author{
Min Liu \\ Durham University, UK
}

\begin{abstract}
Chinese philosophical literature is rarely introduced to foreign countries (Pohl, 1999, p. 303). Zhou Guoping, as a contemporary philosopher and essayist, has created essays with both depth and readability, and thus his works are deemed to be worthy of translation. This article aims to elaborate on the translator's techniques for transferring Zhou Guoping's famous collection of essays $A$ Watchful Distance. Divided into four sections, this article uses actor-network theory as its theoretical framework and analyses the translator's position in translation activities from sociocultural perspective, gives corresponding translating techniques to problems related to creativity, conventionalised expressions, utterances and Chinese cultural elements in this book, and draws a conclusion upon the relationship between cultural homogeneity and corresponding translating techniques underpinned by actor-network theory. By discussing specific translating techniques used for Zhou's book, this article fills up the gap in the transfer techniques of $\boldsymbol{A}$ Watchful Distance to overseas cultures. However, the limitation lies in that the number of Zhou's works studied are restricted.
\end{abstract}

Index Terms - translating techniques, actor-network theory, Zhou Guoping

\section{INTRODUCTION}

A Watchful Distance is a collection of Chinese philosophical essays written by Zhou Guoping. This book is so popular because the thoughts of Zhou provide guidance for, and enhance the spiritual strength of, readers who have encountered difficulties and setbacks in their lives and who are thus confused about the meaning of life. However, Chinese philosophical literature with as much depth and readability as this book is rarely introduced to overseas countries, mainly because certain differences exist in the sociocultural elements embedded in domestic and foreign cultures (Pohl, 1999, p. 303). Few previous articles has incorporated this sociocultural perspective in specific translation techniques, and most of these articles still linger at word-level equivalence, such as Lee (1985) and Bonnie (1991). Therefore, this article intends to use actor-network theory as a pillar to elaborate on how sociocultural gap could be filled in the translation of this book. This article will demonstrate the macro-level analysis, namely the determinants of general translating strategies, and the micro-level analysis, namely the determinants of specific translating techniques.

\section{MACRO-LEVEL ANALYSIS}

The text type of this book, based on Reiss (1989, p. 108), is 'informative' because it was created based on the author's personal experiences and it reflects the author's witty outlook on philosophical issues. Therefore, the translator must ensure that the translation strategies used are to make the translation as plain and explicit as possible.

As Woodward (1977, p. 5) notes, the best essay not only introduces issues of interest to thoughtful readers but also exemplifies the effective combination of rhetorical devices and methods. Based on the pragmatic features of rhetorics in this book, the author divides relevant discussions into the exploration of creativity, conventionalised expressions, utterances and Chinese cultural elements. Given that these four aspects are representative features of the style of this book, the translator chooses them as examples to demonstrate what techniques from sociocultural perspective could be used in the translation of this type of book style.

\section{MiCRO-LEVEL ANALYSIS}

When translating this book, the translator has been guided by actor-network theory (ANT), in which human agency and non-human agency play equally important roles in the construction of actor-networks (Callon and Law, 1997, p. 168). The essence of ANT is to study what factors are involved in the assembly of networks to achieve a specific objective, and during this process what interactions are generated between human and non-human agency. For the specific task of this translation, the translator, as the human agent, must be sufficiently creative to handle various rhetorical devices used in the source text (ST), especially in Chinese poetry. The non-human agencies, mainly cultural norms, conventions and the relations between Chinese and English cultures, have also greatly affected translation decisions. The influence of the translator on cultural factors and vice versa constitutes the translation network and lead to the production of the final translation. Subsequently it will be illustrated the interactions between the translator, a creative translator and several cultural factors. These cultural factors are mainly integrated in Chinese conventionalised expressions, utterances and specific cultural elements such as self-deprecatory terms and category words. 


\section{A. Translation of Creativity}

The translation of creativity refers to the transfer of creative ideas from Chinese to English. As a professional essayist, Zhou is skilled in utilising diverse creative ideas to express himself and attract readers, and he sometimes directly uses Chinese poetry to make his essays more colourful. However, those creative ideas have posed great difficulties to the translator. To transfer the colours of the ST, the translator chooses the techniques of adaptation and imitatation of imagism poetry.

An example that clearly shows the author's creativity is the title Lv+You=Lv You? [Way + Fare = Wayfare?]. In Chinese, 'Lv You' [tourism] is a synonymous compounding disyllable, which means that 'Lv' [travel] and 'You' [tour] contain similar meanings and that the connotation of ' $\mathrm{Lv}$ You' [tourism] is the combination of the meanings of its two syllables (Luo, 2014, p. 22). However, the author's attitudes towards 'Lv' [travel], 'You' [tour] and 'Lv You' [tourism] are completely different. He is positive about 'Lv' [travel] and 'You' [tour] because in his view, these two activities could deepen people's understanding of life. In contrast, his attitude towards 'Lv You' [tourism] is satirical because he believes that tourism has been highly commercialised and that people cannot gain pleasures from it despite spending all their money on it. The question mark at the end of the title indicates his deep doubt about whether the value of 'Lv' [travel] and 'You' [tour] is retained when those two activities are commercialised as 'Lv You' [tourism]. That is, thus, the intention of the author, namely, the assumption that Zhou intends to convey by means of a communicative clue at the semantic level (Gutt, 1991, p. 31). The identification of this assumption is dependent largely upon inference on the part of the translator (Zhang, 2001, p. 289), and the translator aims to achieve optimal relevance by helping the target readers (the TRs) discern the author's intended interpretation without gratuitous efforts (Sperber and Wilson, 1995, p. 158).

However, the contextual assumption intended by Zhou does not exist in the cognitive environment of the TRs; in other words, the translator cannot find lexical equivalents of the title in English. Here, the translator adopts the strategy of adaptation. Although some translation scholars take a negative view of adaptation, criticising it as subverting the 'ideal image' of the ST created by translation (Gorp, 2004, p. 66; Palmer, 2004, p. 262), the translator identify it as a suitable strategy to handle the cross-code breakdown here. As a mediator, the translator uses creation, which is a mode of adaptation to reproduce the author's intention without sacrificing the original formal elements. With the translation Way + Fare = Wayfare?, the translator expresses that although people are on their 'way' and spend much on 'fare' when they are travelling ('wayfaring'), they still cannot enjoy their time as travellers because of their constant haste. The intention of the translator corresponds to the intention of the author. Additionally, since the translator also uses one word (wayfare) containing two morphemes ('way' and 'fare'), the format of translation is also similar to the ST. Although the meanings of "way" and "fare" are not equivalent to 'Lv' [travel] and 'You' [tour], the strategy of creation is adequately relevant to the TRs considering the similar effects produced. By doing so, the translator avoids placing the TRs in a secondary communication situation (Gutt, 1991, p. 73).

The translation of Chinese poetry also necessitates creativity. As an agent in the institutions that have reframed the original writing through translation (Summers, 2014, p. 383), the translator intervenes in the articulation of author function, a framework of textual interpretation (Summers, 2013, p. 11). The translator's participation in the construction of author function is active, since the translator's performance determines the status of the discourse of the ST (Foucault, 1977, p. 123). To ensure that the translator's intervention does not damage the ST image, an attempt is generated to ensure fidelity to the ST and enable the TRs to sense directly the effect and significance of the ST without any unnecessary and overly subjective understanding (Xie, 2014, p. 163). Therefore, the translator chooses to imitate the writing techniques employed by imagists. Compared to English, the Chinese language emphasises the separateness and distinctiveness of singles images and prefers the use of static and non-progressional structures in poetry (Xie, 2014, p. 162). These characteristics meet with imagist poetry style, in which images are objective and can stimulate instantaneous perception (Pound, 1913, p. 200). For example, in 'Shan Xiao Lv Ren Qu, Tian Gao Qiu Qi Bei' [Mountain at dawn, a traveller on the way; a cloudless sky, sadness in the autumn air], the images 'Shan' [mountain], 'Tian' [sky] and 'Qiu' [autumn] are static. Moreover, the combination of these images corresponds to the concept of 'image complex' in imagism because both of them give a 'sense of freedom from time limits and space limits' (Pound, 1913, p. 200). As to formalism, given that free verse logically follows from imagism (Hartman, 1980, p. 134), the translator disregards syntax and metre in translation. By imitating an imagist, the translator acts as an equal party and as the third party in the translation process (Knezevic, 2011, p. 142) contributing to the 'coexistence' of Zhou, the author and the TRs (Ricoeur, 2006 p. 4), and thus provides a positive intervention.

\section{B. Translation of Conventionalised Expressions}

Chinese conventionalised expressions mainly include four-character collocations and idioms. The translation of Chinese four-character collocations, or chengyu will be firstly explored. When considering the chengyu 'Ju An Qi Mei'[A wife lifts the tray to a level with her eyebrows], the translator may originally consider a sociosemiotic approach to translate it. The advantage of adopting this approach is that designative meaning and pragmatic meaning can be emphasised equally. In other words, this approach is relatively comprehensive. As Taylor (1985, p. 223) argues, the designative meaning of lexemes includes the semantic features that define the range of referents in the practical linguistic world, which can be represented by lexemes, and pragmatic meaning refers to the attitudes and values of the 
use context in which those lexemes habitually occur. Given that one significant subset of pragmatic meaning is associative meaning, which implies the association or image that the linguistic signs evoke in readers' minds (Ke, 1996, p. 96), the translator may want to transfer the associative meaning of this chengyu and use images such as 'tray' and 'eyebrow' in the translation. However, those images do not create the idea that the wife is to show great respect for her husband in the minds of the TRs, as in the minds of Chinese readers, because those two groups of readers live in different social contexts. In other words, after the translator encodes the message, the TRs will not decode it as expected and may infer the wrong meaning. Therefore, the better approach is to abandon the transferring of associative meaning and resort to free translation. By rendering this chengyu into 'A wife treats his husband with courtesy', the translator ensures that the TRs will not misinterpret those idiosyncratic signs. As Ke (1996, p. 99) proposes, 'the spectrum of sociosemiotic meanings connected with a sign in one language rarely has a one-to-one correspondence to that of a comparable sign in another language'; thus, the translator mainly makes decisions on what aspects of the meaning of specific signs should be retained and what aspects should be given secondary consideration. Obviously, the translator gives precedence to the most prominent aspect, namely, the designative meaning, to ensure its 'correct transference in whatsoever circumstances and, if no other alternative is available, at the expense of the other meanings of the sign' (Ke, 1996, p. 99).

Secondly the translation of Chinese idioms will be probed. The example cited here is the translation of a typical Chinese idiom: 'Diu Mian Zi' [be disgraced]. In the ST, the context of 'Diu Mian Zi' [be disgraced] is that even if his wife is in the wrong, the husband will not think that he is disgraced when he makes an apology. From the sociopsychological perspective, the husband is taking preventive measures (Goffman, 1959, p. 107) to avoid threats to his wife's face. The natural response of a husband to the need for an apology is to acknowledge his failure to satisfy his wife (Cody and McLaughlin, 1985, p. 55), but the husband in the ST does exactly the opposite and apologises because he considers his wife's wants to be appreciated (Tracy, 1990, p. 218). Thus, he uses strategic self-presentation (Jones and Pittman, 1982, p. 243) to show that he is generous in his interactions with his wife. In other words, by demonstrating that he is not afraid of being dishonoured, he saves his dignity. According to Yu (2001, p. 27), Chinese and English have obvious cross-linguistic similarities in the conceptions of 'Mian Zi' [visage]. In English, 'face' is used to imply a person's position in the 'relational hierarchy' (Chang and Holt, 1994, p. 105), as Mian Zi [visage] in Chinese corresponds to a person's dignity and prestige. Therefore, the translator uses 'face' directly in the translation and translates 'Diu Mian Zi' [be disgraced] as 'lose face'.

\section{Translation of Utterances}

Since the ST belongs to the category of essays, utterances are rarely used by the author. However, those utterances used are no less important than other parts of the ST, as the sentences in quotation marks usually indicate the crucial points. Thus, the translation of utterances is also worth considering.

The utterance that is cited as an example contains only two Chinese characters: 'Shi Wo' [It's me]. Given that the speaker of this utterance produces a statement and accepts it as being or representing what is the case, this utterance falls into the domain of an assertion (Kearns, 2012, p. 120). In relevance theory, the mode of using language in this assertion is the descriptive use of language, in which this language utterance 'is intended to be taken as true of a state of affairs in some possible world' (Gutt, 1998, p. 44). This assertion, included in an illocutionary act abstractly conceived, is a complete intentional act (Kearns, 2012, p. 119). Furthermore, according to Vanderveken (2001, p. 33), if an illocutionary act is performed in an actual context of utterance, then the 'propositional content of the illocutionary act' will fit 'an actual fact in the world'. More specifically, this fit belongs to the 'words-to-world direction of fit' proposed by De Sousa Melo (2001, p. 112). In this example, by using the words 'Shi Wo' [It's me], the author admits that his existence in this world is a fact that cannot be denied.

As noted above, this utterance is an intentional act; thus, the readers of the ST naturally need to use as much information as possible to infer the intention of, or what is implicated by, the speaker or the author. In other words, apart from encoding, transfer and decoding processes, the most crucial point in communication is inference (Sperber and Wilson, 1995, p. 260). In this example, for the convenience of the readers' inference, the author is supposed to obey the 'the maxim of quantity' (Grice, 1989, p. 28) and try to be as informative as he can. However, the author uses only two words in this utterance, which violates Grice's maxim. To thoroughly understand the reason for this use, the translator resorts to the background, namely, the context of this utterance. In relevance theory, the 'context of an utterance' means 'a psychological construct' and concerns readers' assumptions about the world; more specifically, it is 'the set of premises used in interpreting utterance' (Sperber and Wilson, 1995, p. 15). That is, the context of this utterance includes not only the previous text in the book but also the translator's understanding of the world. Therefore, the comprehensive ability of the translator as an actor has a vast impact on the translation. After reviewing the previous text, it could be concluded that Zhou is doubting whether he truly exists in this world and that he deems his existence as a dream. At the end of the essay, however, the author converts to the belief that he does exist in this world, and he answers 'It's me' without hesitation when hearing his name through the telephone receiver. By contrasting his previous doubt with his later firmness, Zhou implies that although people may doubt their existence at times, their existence in this world is an undeniable fact. Zhou violates Grice's maxim for the reason that he wants readers to consider the deep meaning of this utterance by resorting to the context. When translating this utterance, the translator may find it difficult 
to incorporate personal comprehension of the author's train of thought into the translation to help readers understand it; hence, the translator uses literal translation 'It's me' based on the belief that the TRs are sufficiently well educated to have their own understanding of this thought-provoking utterance.

\section{Translation of Chinese Cultural Elements}

Chinese has special cultural elements that may cause cultural barriers to translation, such as self-deprecatory terms and category words that do not exist in English. This section will explore methods to deal with these two aspects.

Self-deprecatory terms play a pivotal role in the depiction of China as 'a land of courtesy', and the author, as a welleducated man, cannot avoid using these kinds of terms when introducing his own works. He describes his famous book on Nietzsche as 'Xiao Ce Zi' [a brochure], but it is actually a very thick book. From the sociopragmatic perspective, self-deprecation is the act of ritual or purposeful disparaging of one's own achievements. In other words, Zhou who uses self-deprecatory terms aims to use their normative function (Leech, 1983, p. 48), their instrumental function (Brown and Levinson, 1987, p. 44), or both. On the one hand, Zhou lives in a society whose norms favour sociality over individuality and one that places 'self' at the bottom of the social hierarchy; on the other hand, by devaluing his possession of such a famous work, Zhou wants to achieve the desired effects of reducing others' envy and avoiding threatening others' face - thus conforming to the 'self-denigration maxim' proposed especially for the Chinese context (Gu, 1990, p. 246). However, this maxim does not apply to Western society, which encourages individualism and competition. With the aim of bringing Chinese heterogeneous cultural elements to the TRs, the translator translates 'Xiao Ce Zi' into 'a little book'. 'Book' truly reflects what the author's work is like, and the modifier 'little' implies the modesty of the author. This translation communicates the intention of using self-deprecatory expressions to the TRs.

Category words carry strong Chinese characteristics. In the example 'Ji You Xi Juan Tian Xia Zhi Shi' [nearly having the tendency to sweeping the whole country], the category words 'Zhi Shi' [the tendency to] are redundant because their meaning is the same as ' Ji' [nearly]. However, the use of these words is necessary in Chinese to achieve clarity of messages in intralingual communication. As Jackson (1974, p. 278) notes, to guarantee the accuracy of the delivered message, the information sender must repeat the message when encoding it to ensure that the information receiver obtains slightly more information than is needed, which is helpful in decoding the message. Nevertheless, the repetition in Chinese is usually unhelpful for English readers and thus needs to be omitted (Wang, 2002, p. 1); otherwise, the English translation easily becomes Chinglish (Pinkham, 1998, p. 15). Therefore, the translation is 'almost sweeping the whole country'. By deleting the repetitive parts, the translator achieves a concise effect.

\section{CONCLUSION}

By exploring the macro-level determinants of translation strategies, and the micro-level translating techniques for creativity, conventionalised expressions, utterances and cultural elements used in this book, the translator concludes that when Chinese philosophical literature is translated, the translation strategies used by the translator (the human agent) are largely dependent on the extent of homogeneity between Chinese and English cultures, which belongs to non-human agencies. Specifically, if these two cultures are highly homogeneous in some aspect, the translator can use literal translation and can rest assured that this type of technique will generally translate the intention of the author and not cause misunderstanding. Conversely, if these two cultures are highly heterogeneous, the translator must give priority to the most important level of meaning at the cost of other aspects of meanings. However, the relations between Chinese and English cultures are not always polarised, and thus, both similarities and differences exist between these two cultures. In this occasion, the translator also uses literal translation in the belief that the TRs are well-educated to have a general understanding of how language is normally used. In this case, the translator also achieves an equivalent interpretation, as long as the translation meets the TRs' expectations of language usage. By discussing specific translating techniques used for Zhou's philosophical essays, this article creatively overcomes relevant barriers via sociocultural approaches, and to some extent fills up the gap in the transfer of this book to overseas cultures. However, the number of Zhou's works studied are limited, and the translating techniques suitable for most of Zhou's works are expected to be explored in future research.

\section{REFERENCES}

[1] Bonnie M. (1991). Problems and Possibilities in Translating Contemporary Chinese Literature. The Australian Journal of Chinese Affairs 25: 37-67.

[2] Brown P and Levinson SC. (1987). Politeness: Some Universals in Language Usage. Cambridge: Cambridge University Press.

[3] Callon M and Law J. (1997). After the individual in society: lessons on collectivity from science, technology and society. Canadian Journal of Sociology 22(2): 165-182.

[4] Chang H and Holt GR. (1994). A Chinese perspective on face as inter-relational concern. In: Ting-Toomey S (ed) The Challenge of Facework: Cross-cultural and Interpersonal Issues. New York: SUNY Press, pp.95-132.

[5] Cody MJ and McLaughlin ML. (1985). Models for the sequential construction of accounting episodes: situational and interactional constraints on message selection and evaluation. In: Street LR and Cappella NJ (eds) Sequence and Pattern in Communicative Behaviour. London: Arnold, pp.50-69.

[6] De Sousa Melo C. (2001). Possible directions of fit between mind, language and the world. In: Vanderveken D and Kubo S 
(eds) Essays in Speech Act Theory. Amsterdam: John Benjamins Publishing, pp.109-118.

[7] Foucault M. (1977). What is an author? In: Bouchard FD (ed) Language, Counter-memory, Practice. New York: Cornell University Press, pp.113-138.

[8] Goffman E. (1959). The Presentation of Self in Everyday Life. New York: Doubleday Anchor.

[9] Gorp HV. (2004). Translation and comparable transfer operations. In: Kittel H, Frank A, Greiner N, et al. (eds) An International Encyclopedia of Translation Studies. Berlin: Gruyter, pp.62-68.

[10] Grice HP. (1989). Studies in the Way of Words. Cambridge: Harvard University Press.

[11] Gu Y. (1990). Politeness phenomena in modern Chinese. Journal of Pragmatics 14(2): 237-257.

[12] Gutt EA. (1991). Translation and Relevance: Cognition and Context. Oxford: Basil Blackwell Ltd.

[13] Gutt EA. (1998). Pragmatic aspects of translation: some relevance-theory observations. In: Hickey L (ed) The Pragmatics of Translation. Clevedon: Multilingual Matters Ltd, pp.41-53.

[14] Hartman C. (1980). Free Verse: An Essay on Prosody. Princeton: Princeton University Press.

[15] Jackson PC. (1974). Introduction to Artificial Intelligence. New York: Petrocelli Books.

[16] Jones EE and Pittman TS. (1982). Toward a general theory of strategic self-presentation. In: Suls J (ed) Psychological Perspectives on the Self. Hillsdale: Erlbaum, pp.231-262.

[17] Ke P. (1996). A sociosemiotic approach to Chinese-English translation. Perspectives: Studies in Translatology 4(1): 91-101.

[18] Kearns TJ. (2012). Two concepts of opposition, multiple squares. In: Béziau JY and Jacquette D (eds) Around and Beyond the Square of Opposition. New York: Springer, pp.119-128.

[19] Knezevic B. (2011). Translator and author in relation to the text. In: Krstanovic VI and Vukanovic BM (eds) The Global and Local Dimensions of ENGLISH: Exploring Issues of Language and Culture. Muenster: LIT Verlag, pp.139-148.

[20] Lee L. (1985). Contemporary Chinese Literature in Translation--A Review Article. The Journal of Asian Studies 44(3): pp. 561-567.

[21] Leech G. (1983). Principles of Pragmatics. London: Harlow.

[22] Luo J. (2014). Study on prosodic morphology of Chinese verbal monosyllabic-disyllabic synonyms. Chinese Lexical Semantics: The 15th Chinese Lexical Semantics Workshop. Macao, 9-12 June. New York: Springer, pp.21-30.

[23] Palmer RB. (2004). The sociological turn of adaptation studies: the example of Film Nior. In: Stam R and Raengo A (eds) $A$ Companion to Literature and Film. Oxford: Basil Blackwell Ltd, pp.258-277.

[24] Pinkham J. (1998). The Translators' Guide to Chinglish. Beijing: Foreign Language Teaching and Research Press.

[25] Pohl K. (1999). Chinese thought in a global context: a dialogue between Chinese and Western philosophical approaches. Leiden: Brill.

[26] Pound E. (1913). A few don'ts by an imagiste. Poetry 1(6): 200-206.

[27] Reiss K. (1989). Text types, translation types and translation assessment. In: Chesterman A (ed) Readings in Translation Theory. Helsinki: Oy Finn Lectura Ab, pp.105-115.

[28] Ricoeur P. (2006). On Translation. London: Routledge.

[29] Sperber D and Wilson D. (1995). Relevance: Communication and Cognition. Oxford: Basil Blackwell Ltd.

[30] Summers C. (2013). What remains: the institutional reframing of authorship in translated peritexts. In: Pellatt V (ed) Text, Extratext, Metatext and Paratext in Translation. Newcastle upon Tyne: Cambridge Scholars Publishing, pp.9-32.

[31] Summers C. (2014). Patterns of authorship: the translation of Christa Wolf's Kindheitsmuster. German Life and Letters 67(3): 378-398.

[32] Taylor C. (1985). Philosophical Papers: Volume 1, Human Agency and Language. Cambridge: Cambridge University Press.

[33] Tracy K. (1990). The many faces of facework. In: Giles H and Robinson PW (eds) Handbook of Language and Social Psychology. Hoboken: Wiley, pp.209-226.

[34] Vanderveken D. (2001). Universal grammar and speech act theory. In: Vanderveken D and Kubo S (eds) Essays in Speech Act Theory. Amsterdam: John Benjamins Publishing, pp.25-62.

[35] Wang J. (2002). From a informatic perspective: Redundancy in Chinese-English translation. Chinese Science and Technology Translators Journal 15(4): 1-4.

[36] Woodward RH and Smith HW. (1977). The Craft of Prose. Belmont: Wadsworth Publishing Company.

[37] Xie M. (2014). Ezra Pound and the Appropriation of Chinese Poetry: Cathy, Translation, and Imagism. London: Routledge.

[38] Yu N. (2001). What does our face mean to us? Pragmatics \& Cognition 9(1): 1-36.

[39] Zhang X. (2001). Pragmatic translation: application of pragmatic theories to translation practices. Modern Foreign Languages 24(3): 285-293.

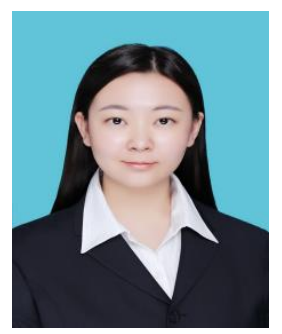

Min Liu was born in Shanxi Province, P.R.China on 31 July 1990. She earned a B.A. from Shanghai Maritime University in Shanghai, P.R.China in 2013 with the major of English translation, and later earned an M.A. in translation studies from Durham University in UK (2016).

Her working experiences include Translator in Shanghai Library and Legal Translator in King \& Wood Mallesons Law Firm. She mainly studies literary translation and legal translation. 